\title{
How to Model Noise Traders Investors Using Prospect Theory
}

\author{
Elder M. Silva, Lydiane Takimoto \\ Department of Economics and International Relations, UFSC, Florianopolis, Brazil \\ Email:elder0055@gmail.com
}

How to cite this paper: Silva, E.M. and Takimoto, L. (2017) How to Model Noise Traders Investors Using Prospect Theory. Open Access Library Journal, 4: e3567. https://doi.org/10.4236/oalib.1103567

Received: March 27, 2017

Accepted: April 22, 2017

Published: April 25, 2017

Copyright ( 2017 by authors and Open Access Library Inc.

This work is licensed under the Creative Commons Attribution International License (CC BY 4.0).

http://creativecommons.org/licenses/by/4.0/

\section{(c) (i) Open Access}

\begin{abstract}
Looking at stock market composition you will see investor which carry their positions for a long time, as well a bunch of investors that change their position many times within a day. The investor which negotiates using intraday strategy is well known as: noise traders (the day trader's). The ways their behavior is simulated into the economic theory today using rules of thumbs for them, and include them in a market with others investors that did not use those rules, but use sophisticated mechanism such as expected value instead. The contribution of the paper to the literature is to offer a unified way to model noise traders. Regularly, agent based models in finance use to different rules to model the behavior into the financial market. One for the skilled investors, and other to more naïve ones. The noise traders would be included in the second group. Our proposal is to model both groups with the same rule.
\end{abstract}

\section{Subject Areas}

Behavioral Economics, Business Finance and Investment

\section{Keywords}

Stock Market, Prospect Theory, Noise Trader

\section{Introduction}

An individual, who made a huge amount of negotiation at the stock market in a short period, trying to pursue all the gain opportunities, will be difficult to replicate into economics models. These individuals are known at our literature as: noise traders. They have no regular strategy, they did not respond to the rational behavior required for the efficient market hypothesis. But they exist, if you look at the real market you will see the day-traders, those whom negotiate at high speed, doing many transactions at the same day. Nowadays, with the automatizations process of the market, including the robots, the clear majority of the ne- 
gotiate of the stock market are conduct by traders with these characteristics. So, it is import to have a good way to reproduce these individuals at our models.

Reference [1] brings us a discussion of what the noise traders are important. From then on, this question has gain importance. The noise traders could lead the market distant from the results you should expect if the marker was efficient. This means, if you believe the stock market is efficient, but the data did not seem to agree with you, this could be because the interference of the noise traders. They trade so fast that the volume of the market is affect. They did not use evaluations methods, so their negotiations may drive the prices away from the fundamental price.

The noise traders are those investors that made their investment decision without a clear rule. As pointed out by [1], if the investors had perfect rationality they would know that they should not trade on noise, or use popular models to take decisions. For us, the noise traders will be defined as the traders each open and close their positions faster. That represents in the real stock market the investors each use day-traders' strategies, or automatized their actions via algorithmic traders.

A well understanding of the behavior of the stock market is important for the police makers and for the investor. There are some strategies in applied finance which try to study the properties of the stock market, see, e.g., [2]. Here we will talk about the model that tries to simulate a stock market using agent based models. Doing so, it is possible to try different strategies of regulations, if you are thinking as a police maker, or different strategies of investments, if you are at the side of the investors. A regular way to do that would be to use an artificial stock market.

The long continue artificial stock market we have run probably is the SFIASM (Santa Fe Institute Artificial Stock Market). In this type of model a virtual stock market is created, agents negotiate with each other; the series of prices and volume emerge as results of their interactions. Reference [2] is one example of this work, to replicate the market, with investor which are rational and the noise traders; they included a simple way for noise traders to negotiate. The usual agent, representing the rational investor, which will use a structured rule to choose when to buy or sell using the expected value for the asset; while the noise trader will use some rule of thumb to choose their moves. This can replicate the series of prices and returns we see in the real market, see, e.g., [2] and [3].

The importance of the robot traders and their impact at the market could be seem at [4]. They also suggest the robots could be used as a toll by the police makers to reduce the volatility of the stock market. For [1], this excess of volatility present in the stock market was triggered by the noise traders. Their works also use the agent based model to study the stock market.

An alternative way to see the behavior of the investor arises with the Prospect Theory ([5] [6]). This is because the Prospect Theory measures gains and losses with different equations, based on real experiments which suggest real humans do behave differently when exposed to gains or losses. Compare with the beha- 
vior needed to support the efficient market hypothesis, this is completely different. It will not emerge an efficient market from individuals that do behave as the Prospect Theory suggest.

We think the prospect theory is a good choice to model financial decision. That is because the prospect theory was developed above a different group of hypotheses than the neoclassical approach. With the prospect theory, the agent makes a probabilistic choice under risk situation. The core hypothesis of the theory is that the behavior under gains and losses is different. That will means if the value of one operation is positive the behavior will be of one kind, and if the operation turns negative, the behavior of an individual will change. In resume, the reference point, the start point, matters in this scenario.

What we do in this paper is put together the agent based model with the Prospect Theory and use one parameter present at the Prospect Theory to model agents that represents both type of investor: the noise traders; and the long-time investors.

The specific parameter which will be our interest here is that one which deal with the risk aversion of the individual. The Prospect Theory was tested in the field, their parameters were calibrated with experiments; results shown that the average individual fell their losses more than twice as their gains. That means, a typical individual is risk aversion, because losses cause more impact than the respective gain. All this teach us the reference point is import, gains or losses are relative measures, you need to have some start point to evaluate your current position. In the stock market this do exist; the start point is the price the investor pay to open their position. What we will do is study how the variety of risk aversion may influence at the behavior of the agents into the stock market and use this to calibrate our agents: as noise traders or long time investors.

The agent based model we use were presented in [7]. The model was settled in a way to simulate the disposition effect and their interaction with stop loss' rules. This model showed capable of to replicate stylized facts, such as: clusters of volatility; volume of negotiation respond to the volatility; skewness and kurtosis of the series of returns match with the observed ones. We will describe here the core sections that will influence our goal, the code can be download at http://modelingcommons.org/account/models/712. After we present the model will be shown the results of the experiments, following by a brief conclusion of our work.

\section{Modeling Noise Traders with Prospect Theory}

We assume the agents will pursue profit and measure their utility from the Prospect Theory. That is because the agent respond to the Prospect Theory equation, i.e., the agent was program using the Equation (1). In this way, the agents will behave between two different options, first when the agent is pursuing a gain; second, when the agent had a loss in their transaction. So, we need to look at the equation that resume the behavior in this theory ([5]): 


$$
v=\left\{\begin{array}{l}
x^{q} \quad \text { if } \quad x \geq 0 \\
-\lambda(-x)^{\beta} \quad \text { if } \quad x<0 .
\end{array}\right.
$$

The $\lambda$ will be parameter that interest us, it measures how much the loss environment differ from the gain one. The $v$ represents the utility perceived by the individual and the $x$ represents the result of an event. If the $x \geq 0$ the individual is the reign of the gains, but if the results are lower than zero this means we are at the losses environment. The parameter of this equation was measured by [6]. They found $\alpha=\beta=0.88$; and the value of $\lambda=2.25$. The parameters $\alpha$ and $\beta$ are related to the concavity of the utility function, we will not change their value. But we intend to change the value of the $\lambda$ and see what happen.

The experiment will occur as follow. In the model, we have ten thousand agents, each one program using this equation to respond to the market fluctuation. We run simulations with 3000 periods each, and change the value of $\lambda$ from one run to another. The agent may buy or sell one asset. After he open a position he waits a few periods until finish their transaction. At the end of each simulation we can measure how much time each agent dispends per transaction. Than we take the average to see the typical duration of a transaction for each value of $\lambda$. The $\lambda$ is well defined by values higher than one, but we also run simulations for values between zero and one, for this values the agents became risk taker, instead of risk aversion.

The Prospect Theory deal with the behavior of the agent after he open a position. When it has a possession of the asset, it uses the initial price as the referential point. From there it will achieve their utility using the Equation (1). But before that, when the agent need decide what and when to buy something, the way to model it is free. For example, you may use some rule that measure the expected value of the asset or something equivalent.

In the model, we are presenting here, the agents decide when to open a position using a behavioral rule, one which was inspired from biology ([8]). Our agents are dispersed into a continues grid, a toroid one, with eight neighbors. The agents sometimes will have a personal information about the market; extracted from their last operation. If the agent had bought at the previous period, that means, he has a personal information which represents buy. If it had sell, then the personal information will be that the market is getting down. If it did nothing in the previous period, the personal information of the agent will be null. This is all we need to use to apply the Equation (2). To decide what to, buy, sell, or do nothing; when the agent has no asset, he uses the equation bellow:

$$
\gamma_{i t}^{b}=\left\{\frac{\sum_{j=1}^{8} b_{i j}+\omega O_{i}}{\sum_{j=1}^{8}\left(b_{i j}+s_{i j}+h_{i j}\right)+\omega O_{i}}\right.
$$

This equation tells the probability of an agent to buy at that period $t$. The personal information we were talking before is represent by $O_{i}$, it is regulated by the $\omega$. As in [8] we use $\omega=1$. The information collected with the neighbors, buy, sell, or do nothing, are respectively: $b_{i j} ; s_{i j} ; h_{i j}$. Which is binary, one if the 
neighbor has that information, zero otherwise. For the details please check the full model presented in [7]. The next section will show the results collected from the simulations.

\section{Results}

All data utilized in this work was generated using the model presented in [7]. In Figure 1 we see the evolution of mean duration of the transactions through the different values of $\lambda$. As each simulation was run for 3000 periods, the maximum duration of one transaction must be 3000 . We study values of $\lambda$ between 0.1 and 3.0. For values of $\lambda<1$ the agent is a risk taker, and their transactions was finishes quickly. The minimal value, one period, would represent the agent buy the asset and sell it in the next period.

Table 1 shows us a resume of the experiment. For $\lambda=3.0$, e.g., the average duration of a transaction was above one thousand; that means, the agent with

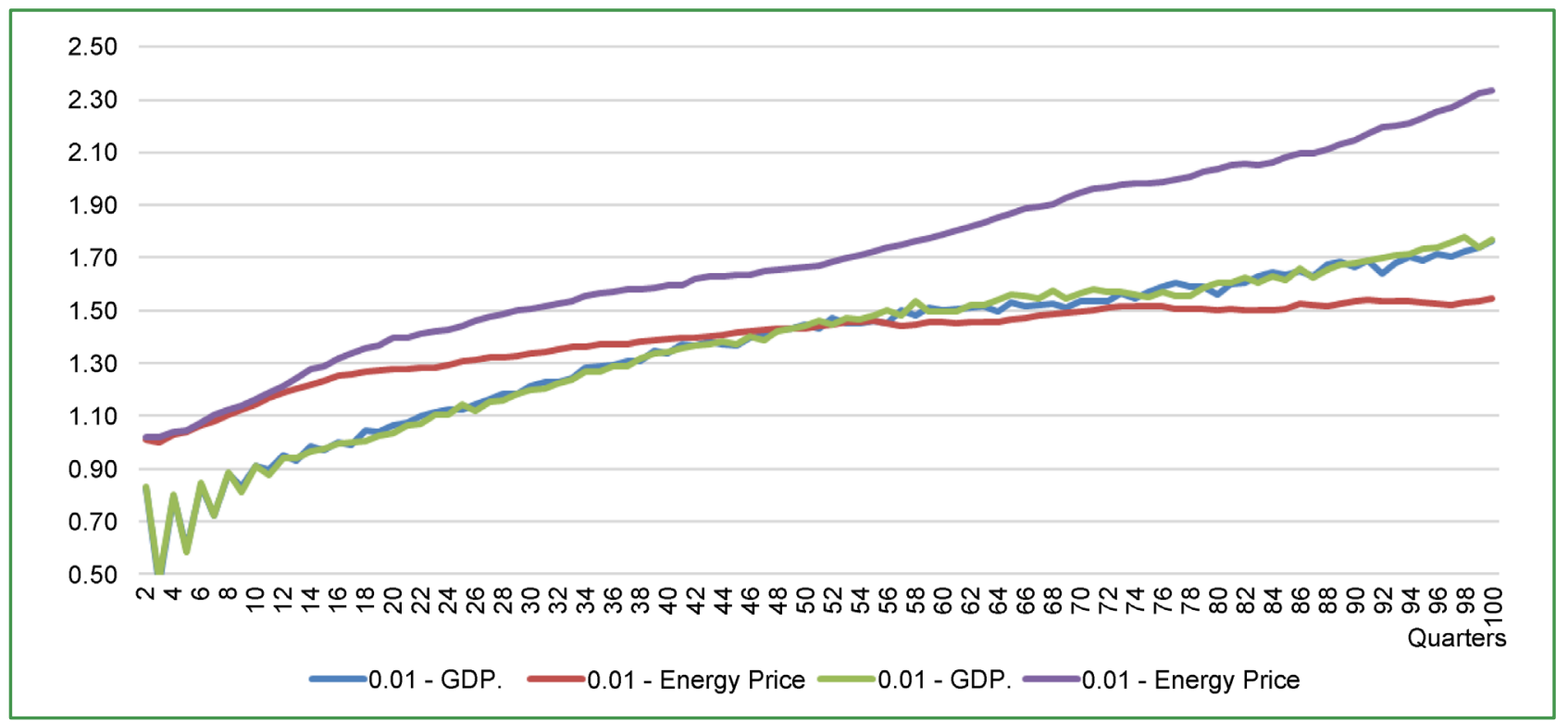

Figure 1. Energy price and the real GDP, values are an average of ten simulations for each value of rainfall shock: 0.01 and 0.10 .

Table 1. Mean duration of the transactions as function of $\lambda$. Results are an average of the agents with each type of $\lambda$. For low values of $\lambda$ the agents do a lot of transactions during a simulation. Maximum duration of a transaction would be 3.000 .

\begin{tabular}{cc}
\hline$\lambda$ & Mean duration of transactions $\left(^{*}\right)$ \\
\hline 0.1 & $1.36( \pm 0.01)$ \\
0.5 & $6.57( \pm 0.21)$ \\
1.0 & $46.91( \pm 6.44)$ \\
1.5 & $377.60( \pm 79.5)$ \\
2.0 & $712.08( \pm 156)$ \\
2.5 & $1065.20( \pm 196)$ \\
3.0 & $1233.40( \pm 236)$ \\
\hline
\end{tabular}

${ }^{*}$ Confidence interval of $95 \%$. 
this $\lambda$ made less than three transactions during the simulation. Each simulation had 3000 periods and agents with the lowest $\lambda$ negotiated almost every period.

Another information which is useful to look at is the volume of negotiation. As noted by [1] the increase in the volume of transaction is one of the characteristics of a marker with a presence of a noise trader. To check that we count all trades which occur in each simulation. It is expected the volume of negotiation could be higher at by the lowest values of $\lambda$, it is because we assume there is where the noise traders are. In Table 2 we have the results. The volume raise from twenty-four thousand, to twenty-two millions of transactions. If we normalize by the lowest volume, it is, assume $\lambda_{3.0}=1$, we see the volume for $\lambda_{1.0}$ is 906 bigger.

The major properties appointed by the literature could be replicated by this mechanism. The results of the simulations show it is possible increase velocity, agents traders fasters, with low value of $\lambda$. In [6] the value of $\lambda$ is just define above one. We here let $\lambda$ be lower than one, but even if we assume only $\lambda \geq 1$ our conclusions may hold.

\section{Conclusions}

We think a good way to simulate noise traders' investors could be using the Prospect Theory with an adapted $\lambda$. This bring the advantaged that we can also model the non-noise traders' investors with the same rule, just with a different value for $\lambda$; rather than was made before using rules of thumbs for noise traders and more complex approach for sophisticated investors.

The main contribution of this work has been to explore the possibility to model two important types of investors with the same rule of behavior. In financial models, usually the agents are divided into groups, with different sets of rules to govern their behavior. We find it is possible to mimic the investor: with long-term strategy (agents which keep their position for more them a thousand periods), and the day-trader strategy (agents which finish their position within a few periods) using the same rule.

Using a model with an ecology of $\lambda$, it is, using agents with different value of $\lambda$ in a single simulation could replicate the market properties. The calibration of each proportion of $\lambda$ uses, e.g., more noise traders with a few long-term investors,

Table 2. Comparing the volume of negotiation for different $\lambda$. The bigger volume of negotiation occur with $\lambda=0.1$, which was 906.9 times the volume of $\lambda=3.0$.

\begin{tabular}{ccc}
\hline$\lambda$ & Total of transactions & Volume of Transactions, $\lambda_{3.0}=1$ \\
\hline 0.1 & $22,058,824$ & 906.9 \\
0.5 & $4,566,210$ & 187.7 \\
1.0 & 639,522 & 26.3 \\
1.5 & 79,449 & 3.3 \\
2.0 & 42,130 & 1.7 \\
2.5 & 28,164 & 1.2 \\
3.0 & 24,323 & 1.0 \\
\hline
\end{tabular}


was not settled in this work and could be one improvement for futures works. Also, this work only uses the Prospect Theory only when an agent has an opened position. When the agent has no assets, and need to decide whether to open a position it uses an adaptive rule to do so. In the future, this could be changed, perhaps including the Prospect Theory also at the moment to begging an operation and not only at the moment to end one.

\section{Acknowledgements}

We would like to thank CAPES (Coordenação de Aperfeiçoamento de Pessoal de Nivel Superior, Brazil) for financial support.

\section{References}

[1] Shleifer, A. and Summers, L.H. (1990) The Noise Trader Approach to Finance. The Journal of Economic Perspectives, 4, 19-33. https://doi.org/10.1257/jep.4.2.19

[2] Arthur, W.B., et al. (1996) Asset Pricing under Endogenous Expectations in an Artificial Stock Market. SSRN, 2252, 1-27.

[3] Vacha, L., Barunik, J. and Vosvrda, M. (2012) How Do Skilled Traders Change the Structure of the Market. International Review of Financial Analysis, 23, 66-71. https://doi.org/10.1016/j.irfa.2011.06.011

[4] Suhadolnik, N., Galimberti, J. and Da Silva, S. (2010) Robot Traders Can Prevent Extreme Events in Complex Stock Markets. Physica A: Statistical Mechanics and Its Applications, 389, 5182-5192. https://doi.org/10.1016/j.physa.2010.07.025

[5] Tversky, A. and Kahneman, D. (1991) Loss Aversion in Riskless Choice: A Reference Dependent Model. The Quarterly Journal of Economics, 106, 1039-1061. https://doi.org/10.2307/2937956

[6] Tversky, A. and Kahneman, D. (1992) Advances in Prospect Theory: Cumulative Representation of Uncertainty. Journal of Risk and Uncertainty, 5, 297-323. https://doi.org/10.1007/BF00122574

[7] Silva, E.M. and Da Silva, S. (2015) Offsetting the Disposition Effect with a Stop-Loss Rule. Mathematical Finance Letters, 1-13.

[8] Couzin, I.D., et al. (2005) Effective Leadership and Decision-Making in Animal Groups on the Move. Nature, 433, 513-516. https://doi.org/10.1038/nature03236 
Submit or recommend next manuscript to OALib Journal and we will provide best service for you:

- Publication frequency: Monthly

- 9 subject areas of science, technology and medicine

- Fair and rigorous peer-review system

- Fast publication process

- Article promotion in various social networking sites (LinkedIn, Facebook, Twitter, etc.)

- Maximum dissemination of your research work

Submit Your Paper Online: Click Here to Submit

Or Contact service@oalib.com 